\title{
TUTELA JUDICIAL EFECTIVA Y REVISIÓN EN CASACIÓN DEL USO DE LA FACULTAD JUDICIAL DE MODERACIÓN DE LA RESPONSABILIDAD POR NEGLIGENCIA PREVISTA EN EL ART. 1103 DEL CÓDIGO CIVIL
}

Effective remedy and review in cassation of the judicial powers of moderating the fault liability foreseen in article 1103 of the Spanish Civil Code

\author{
ANTONIO GONZÁLEZ VALVERDE \\ Universidad de Murcia \\ agonval@um.es
}

Cómo citar/Citation

González Valverde, A. (2021).

Tutela judicial efectiva y revisión en casación del uso de la facultad judicial de moderación de la responsabilidad por negligencia prevista en el art. 1103 del Código Civil. Derecho Privado y Constitución, 39, 365-399. doi:https://doi.org/10.18042/cepc/dpc.39.05

(Recepción: 23/08/2021; aceptación tras revisión: 20/10/2021; publicación: 10/12/2021)

\section{Resumen}

La facultad de moderación judicial de la responsabilidad por el incumplimiento negligente de las obligaciones prevista en el art. 1103 CC es considerada jurisprudencialmente una decisión discrecional del juez de instancia, basada en la equidad y dependiente de las circunstancias del caso que, salvo excepcionalmente, no es susceptible de revisión en casación. Este artículo examina los supuestos de excepción a esa regla y la necesidad de preservar el carácter discrecional de las decisiones evitando, al mismo tiempo, la arbitrariedad. Este equilibrio precisa, de un lado, la exteriorización de los parámetros de aplicación o inaplicación de la facultad de moderación y, de otro, una motivación suficiente de la decisión judicial, que recoja los elementos fácticos y jurídicos que permitan valorarla y que hagan posible, con carácter general, 
el control jurisdiccional de las decisiones, conforme al contenido y función propios del derecho a la tutela judicial efectiva.

\section{Palabras clave}

Art. 1103 CC; casación; moderación judicial de la indemnización; discrecionalidad y arbitrariedad; tutela judicial efectiva.

\section{Abstract}

The power of judicial moderation of responsability for negligent breach of obligations provided in Article 1103 CC is considered in case law to be a discretionary decision of the trial judge, based on equity and depending on the circumstances of the case, which, except in exceptional cases, is not subject to appeal in cassation. This article studies the exceptions to this rule and the need to preserve the discretionary nature of the decisions while avoiding arbitrariness. This balance requires, on the one hand, the externalization of the parameters of application or non-application of the power of moderation and, on the other hand, a sufficient motivation of the judicial decision, which includes the factual and legal elements that allow to evaluate it and make possible, as a general rule, the jurisdictional control of the decisions, in accordance with the content and function of the right to effective judicial protection.

\section{Keywords}

Article 1103 CC; cassation; judicial moderation of compensation; discretion and arbitrariness; effective access to justice. 


\section{SUMARIO}

I. INTRODUCCIÓN: LA FACULTAD JUDICIAL DE MODERACIÓN EN CASO DE INCUMPLIMIENTO NEGLIGENTE DE LA OBLIGACIÓN PREVISTA EN EL ART. 1103 CC: 1. Antecedentes. 2. La facultad de moderación del art. 1103 CC como excepción al principio de reparación íntegra del daño. 3. La desproporción entre la entidad del daño y la propia conducta negligente como fundamento de esta facultad. II. EL CARÁCTER DISCRECIONAL DE LA FACULTAD JUDICIAL DE MODERACIÓN Y LA EXCLUSIÓN GENERAL DE LA REVISIÓN CASACIONAL: 1. El carácter discrecional de la facultad de moderación del art. 1103 CC. 2. La función propia del recurso de casación. III. SUPUESTOS DE ADMISIÓN DEL CONTROL CASACIONAL. IV. LÍMITES A LA DISCRECIONALIDAD JUDICIAL: «DISCRECIONALIDAD PERMITIDA» VS. «DISCRECIONALIDAD ARBITRARIA». V. LA REVISIÓN CASACIONAL POR INCUMPLIMIENTO DEL DEBER DE MOTIVACIÓN EN USO DE LA FACULTAD DEL ART. 1103 CC.: 1. La exigencia de motivación de las decisiones y el control de la potestad discrecional del art. 1103 CC. 2. Tutela judicial efectiva y función de control casacional de los pronunciamientos discrecionales, facultativos o de equidad. La expresión de los parámetros de decisión. 3. La justificación de la forma en que se alcanza el quantum indemnizatorio. 4. Conclusiones. Biblografía.

\section{INTRODUCCIÓN: LA FACULTAD JUDICIAL DE MODERACIÓN EN CASO DE INCUMPLIMIENTO NEGLIGENTE DE LA OBLIGACIÓN PREVISTA EN EL ART. 1103 CC}

\section{ANTECEDENTES}

La posibilidad de moderación judicial de la indemnización en los casos de incumplimiento negligente de las obligaciones no se recoge en el Código Civil hasta el anteproyecto de $1882-1888^{1}$. El Proyecto de 1851 se había limitado a reconocer en su art. 1011.2 ${ }^{\circ}$ la negligencia como fuente de la obligación de indemnización de perjuicios y en el art. 1013, cambiando el criterio del Proyecto de 1836, a la procedencia de la responsabilidad derivada

1 Para los precedentes normativos del precepto en nuestro derecho, véase Díaz Alabart (1989: 476 y ss.). 
de negligencia «en todos los contratos, cuando no se ha puesto la diligencia que se hubiere pactado. $y$, en su defecto, la que es propia de un buen padre de familia» ${ }^{2}$; pero ni en este texto ni en el derecho histórico anterior puede rastrearse el reconocimiento de una facultad judicial de moderación en atención a las circunstancias.

No obstante, Gutiérrez (1869: 58 y ss.) $)^{3}$ recoge el debate doctrinal que al tiempo de la publicación del Proyecto de 1851 suscitó la propuesta de abandonar la doctrina clásica de los tres tipos de culpa a favor de una clasificación que admitía solamente dos especies: «una que se mide y se gradúa por la que acostumbra emplear un hombre atento a sus deberes y otra que se mide por la que el deudor de quien se exige o que ha de prestarla acostumbra a emplear en sus propios negocios".

En el Anteproyecto de 1882-1888, cuyo art. 1120 coincide con la redacción del vigente art. 1103 CC ha desaparecido ya la alusión a la diligencia debida referida al pacto o a la propia de un buen padre de familia. Si en la valoración de esta última podía entenderse implícita, a falta de pacto, la valoración judicial de la culpa y, en su caso, la moderación de la indemnización debida, lo cierto es que no se recogió en el preceptót.

\section{LA FACULTAD DE MODERACIÓN DEL ART. 1103 CC COMO EXCEPCIÓN AL PRINCIPIO DE REPARACIÓN ÍNTEGRA DEL DAÑO}

El art. 1103 del Código Civil establece que «la responsabilidad que proceda de negligencia es igualmente exigible en el cumplimiento de toda

2 García Goyena (1852: 49) considera que, «[...] desterradas ya las tres especies de culpas o negligencias debe ser rarísimo e incluso inútil el pacto especial para el caso de este artículo». La responsabilidad procedente de dolo del art. $1102 \mathrm{CC}$, en cambio, figuraba ya en las Partidas (ley 29, tit. II, Partida 6º).

3 Recogiendo las opiniones favorables a graduar la diligencia en función de la pertenencia de la cosa objeto del contrato y del interés predominante en el mismo. Se refiere Gutiérrez al discurso 59 francés en el que sí tiene entrada el empleo de la equidad por el juez, que haría innecesarias ulteriores reglas y clasificaciones de la negligencia. La misma idea se encuentra en De Diego (1930: 25).

4 Por la dificultad para rastrear sus antecedentes, el art. 1103 CC ha sido calificado de «misterioso». Díaz Alabart (2016: 63-65) sitúa su origen en una suma de influencias del Code y de los Códigos portugués y argentino. Para Pantaleón (1991: 1038), el precepto sigue las tesis de Pothier en su Traité des Oligations (nn. 164 y 165), quien entendió que la previsibilidad exigible a las partes al celebrar el contrato sobre la responsabilidad contractual no dolosa se refería «a los tipos o causas de eventos dañosos de cuya indemnización se trate». 
clase de obligaciones, pero podrá moderarse por los Tribunales según los casos».

La culpa en el art. 1103 CC se configura como una situación subjetiva frente a la infracción obligacional, es decir, como ausencia de una voluntad dirigida a contradecir y negar el vínculo jurídico, según confirman los términos del art. $1107.1^{\circ}$ CC. En este sentido, la culpa concebida subjetivamente se formula en el art. $1103 \mathrm{CC}$ al mismo tiempo negativamente, por oposición al 1102 CC, y positivamente, a partir de la diligencia infringida, que no está ligada al cumplimiento de la obligación o cualquier otra función obligacional que la pueda objetivar; es decir, se concibe como una diligencia en abstracto que debe entenderse como «esfuerzo, atención o cuidado» y, situada en el contexto de los arts. 1101 y 1103 CC, como infracción del esfuerzo o atención debidos 5 .

El precepto equipara la responsabilidad procedente de negligencia a la que procede de dolo (art. $1102 \mathrm{CC}$ ) en cuanto a la exigibilidad, pero reserva la posibilidad de moderación judicial exclusivamente a la primera. Se reconoce así la posibilidad de la intervención de los tribunales en la determinación de la responsabilidad por negligencia, que, en función de las circunstancias del caso, pueden hacer o no uso de dicha facultad y, haciéndolo, fijar el quantum de la indemnización.

La misma redacción de la norma, propia de un sistema de responsabilidad que atiende fundamentalmente al grado de culpa, facilita esta interpretación, acogida por la jurisprudencia ${ }^{6}$, que configura la posibilidad de moderar la indemnización como una facultad de la instancia aplicable tanto a la responsabilidad contractual como a la extracontractual ${ }^{7}$, sujeta a la valoración de las circunstancias concurrentes en cada caso.

La posibilidad de moderación judicial de la indemnización prevista en el art. 1103 CC se restringe, pues, a los supuestos en los que interviene algún tipo de culpa o negligencia, es decir, aquellos en que el deudor no ha observado en el cumplimiento de las obligaciones el cuidado y la diligencia debidas, realizando sin malicia un acto o una omisión determinante del incumplimiento. Implica, por lo tanto, buena fe, o, al menos, falta de mala fe, consistente en

\footnotetext{
Badosa Coll (1987: 69, 680 y ss.).
}

6 Guilarte Martín-Calero (1999) estudió esta tendencia jurisprudencial a atender al grado de culpa al tratar de los criterios de moderación, valorando la facultad del art. 1103 CC como límite al principio de reparación íntegra del daño.

7 En contra, con distintos argumentos, Borrel Macía, De Ángel, O'Callaghan, Pantaleón y Albaladejo (2005: 5-24), quien achaca a la jurisprudencia que aplica el precepto al campo extracontractual la falta de un criterio y un uso injustificado de la equidad. 
la ausencia de una intención de vulnerar el deber de prestación, con exclusión de los supuestos en que interviene dolo (art. $1102 \mathrm{CC}$ ), pues el que dolosamente incumple o cumple mal su obligación, ha de responder íntegramente de los daños que deriven de su actuación (art. 1107 CC), y sin posibilidad de moderación.

La mayor gravedad del incumplimiento doloso se hace patente también en el hecho de que la responsabilidad que deriva del mismo se considera de orden público y por lo tanto no admite la renuncia anticipada del acreedor (art. 1102), en tanto que nada impide pactar anticipadamente la renuncia a exigir la responsabilidad derivada de la simple culpa, y trasciende a la extensión de los daños resarcibles en los términos del art. 1107 CC $^{8}$.

El reconocmiento por el art. 1103 CC dela facultad judicial de moderación de la responsabilidad «en toda clase de obligaciones» ${ }^{9}$, ha permitido otorgar a la norma una «fuerza expansiva» que fundamentaría su aplicación a múltiples supuestos. De hecho, la norma se utiliza como un recurso general que autoriza la actuación discrecional del juez sobre la base de la equidad y que resulta aplicable —o al menos se aplica de facto — a una amplia variedad de obligaciones procedentes de acciones u omisiones que causan daño, con el límite de los supuestos en que intervenga una conducta dolosa.

Díaz Alabart (1988: 1222) puso de relieve que el precepto constituye un auténtico «cajón de sastre» y que se aplica jurisprudencialmente, a menudo incorrectamente, a una amplia variedad de supuestos en los que por cualquier razón se entiende que la equidad aconseja rebajar la indemnización a cargo de quien debe satisfacerla, ajustando su importe al daño realmente producido o a la parte del mismo realmente causado por quien aparece obligado a repararlo. En este mismo sentido, Albaladejo (2005: 14) advierte que la jurisprudencia, en aplicación del precepto, a menudo no modera, sino que simplemente distribuye o cuantifica el importe de la indemnización cuando entiende que esta es la solución más equitativa.

Entre esta variedad de supuestos se encuentran los de concurrencia de culpas en el resultado dañoso, en los que la jurisprudencia aplica el art. 1103 CC «por vía de generalización», esto es, a falta de norma específica, cuando

8 SSTS de 23 de octubre de 2012 y de 20 de abril de 2011, RDGRN de 28 de julio de 2016.

9 En opinión de Badosa Coll (1993: 39), con la expresión «en toda clase de obligaciones» el precepto se está refiriendo a la clasificación de las mismas según sus fuentes (arts. 1089 a 1094 CC). 
existe participación en el resultado dañoso de más de un autor, ${ }^{10} \mathrm{o}$ aquellos en que se emplea para cuantificar el importe de la indemnización reduciéndolo respecto del solicitado ${ }^{11}$. Aunque con menor frecuencia, se utiliza también para moderar la responsabilidad derivada del daño moral ${ }^{12}$, en supuestos de responsabilidad civil derivada de delito ${ }^{13}$, en relación con la validez o no de las cláusulas indemnizatorias por resolución unilateral de los contratos de arrendamiento para establecer un mínimo de indemnización ${ }^{14}$, con el fin de evitar un enriquecimiento injusto o para moderar la indemnización reclamada en caso de concurrir un incumplimiento no esencial, pero sí relevante, de las obligaciones ${ }^{15}$.

\section{LA DESPROPORCIÓN ENTRE LA ENTIDAD DEL DAÑO Y LA PROPIA CONDUCTA NEGLIGENTE COMO FUNDAMENTO DE ESTA FACULTAD}

La moderabilidad de la indemnización recogida en el art. 1103 CC ha de entenderse como una excepción al principio general de reparación plena o íntegra de la cuantificación objetiva del daño probado, que tiene en nuestro ordenamiento carácter imperativo, situándose fuera del ámbito de la autonomía privada ${ }^{16}$.

Señala Ossorio Morales (1988: 119-110) que la del art. 1103 CC es una norma flexible que permite a los tribunales medir discrecionalmente las consecuencias del acto culposo y cuya justificación radica en la dificultad de establecer a priori el grado de responsabilidad en que debe incurrir quien obra negligentemente, pues en el cumplimiento de las obligaciones hay que poner

10 Muy frecuentemente en el ámbito laboral cuando el exceso de confianza o la imprudencia de la víctima contribuyen a los daños sufridos. Decisiones recientes consideran que la concurrencia de culpas tiene apoyo, además, en el art.1902 CC (SSTS 334/2007, de 21 de marzo y 270/2021 de 6 de mayo de 2021).

11 Aunque se trata de conceptos distintos, pues una cosa es fijar la cuantía de los daños producidos y otra moderar, si procede, dicha cantidad de modo que no se satisfaga por entero por la levedad de la culpa que causa el perjuicio (Albaladejo, 2005: 14).

12 SAP Pontevedra 534/2019, de 7 de octubre.

13 SAP Barcelona, 13, 87/2019, de 22 de abril, en aplicación de la facultad de moderación del art. 114 CP.

14 SAP Murcia, $1^{\circ}$, de 10 de febrero de 2010.

15 Como hace la STS 4/2021 de 13 de enero. No procede, en cambio, cuando la acción ejercida no es una acción de reclamación de daños y perjuicios, sino de cumplimiento (STS 183/2016, de 18 de marzo, ATS de 24 de marzo de 2021). Véase Rodríguez-Rosado (2016: 45-57).

16 STS de 14 de julio de 2005. 
la diligencia necesaria para no lesionar el derecho ajeno, pero es difícil graduar con exactitud qué diligencia es exigible.

Como constatación de esta dificultad, la facultad prevista en el art. 1103 CC tiene su fundamento último en una aplicación práctica de la equidad, que se traduce en la moderación del quantum indemnizatorio debido a la menor culpa de quien causa el daño. La jurisprudencia lo ha declarado así reiteradamente, entendiendo que es la equidad el principio cuyo espíritu preside y justifica el precepto como forma de evitar un resultado injusto ${ }^{17}$. La jurisprudencia menor ${ }^{18}$ alude a veces a un criterio de "prudencia» para fundamentar el uso de la facultad moderadora, especialmente en ausencia de criterios objetivos que permitan la determinación de la indemnización en la cuantía reclamada.

La aplicación práctica de la equidad descansa en la desproporción entre el daño causado y la propia conducta negligente que lo ha ocasionado ${ }^{19}$. Es esta desproporción la que hace que no resulte equitativo condenar al agente a reparar la totalidad del daño, de forma que el juez, incluso de oficio, puede discrecionalmente moderar la indemnización en atención a las particularidades del caso, sin que para ello sea obligada la apreciación de concausas o concurrencia de actitudes culposas o negligentes ${ }^{20}$.

Es la propia naturaleza del derecho de daños la que determina que «una misma acción u omisión puede causar daños de distinta entidad y cuantía, debiendo ser reparados con independencia de dicha cuantía por el mero hecho de ser responsable de los daños causados por acciones u omisiones culpables o negligentes» (Plaza Penadés, 2016: 112). Puede decirse entonces que la equidad actúa aquí como un remedio al desequilibrio que en las posiciones respectivas de las partes provoca la presencia causal de una negligencia de un grado muy menor en proporción al daño producido, desproporción que justifica la intervención discrecional del tribunal moderando la indemnización que generalmente correspondería; de este modo se evita hacer responsable al deudor de los daños en «una cuantía excesiva, que no había sido prevista y, por tanto, ni asumida ni garantizada por el deudor» (Pérez Velázquez, 2016: 441-442).

17 SSTS de 20 de junio de 1989, 19 de febrero de 1990, 20 de abril de 1993, 24 de noviembre de 1995 y 29 de septiembre de 2005, entre otras.

18 SAP Palencia, $1^{\mathrm{a}}$, de 14 de marzo de 2019, SAP Zamora, 1a, de 8 de marzo de 2019.

19 Pothier (1839: 98-99) hace referencia a esta desproporción, señalando que en tales casos la indemnización a cargo del deudor «no deben justipreciarse con todo rigor» (164), con el objeto de atribuir al juez la facultad de moderación en los casos de imprevisibilidad del resultado dañoso cuando los daños son excesivos.

20 SSTS de 20 de junio de 1989, 20 de abril de 2011, 23 de octubre de 2012 y 19 de febrero de 2014. 
El resultado práctico es que la aplicación del art. 1103 CC requiere la concurrencia de elementos que hagan posible apreciar la necesidad de una solución equitativa, y esto no sucede siempre. No es posible, por ejemplo, cuando no se acredita actuación negligente, ni siquiera en grado mínimo ${ }^{21}$, o cuando abiertamente puede calificarse de dolosa.

También el elemento de la buena fe resulta decisivo en la fundamentación de la facultad de moderación judicial acogida en el art. 1103 CC. Afirma Badosa Coll (1993: 40) que es la valoración de este elemento y no la gradualidad de la propia diligencia lo que sirve de soporte a esta facultad, pues el art. 1103 CC aporta «una nota "cuantitativa» a la buena fe, en el sentido de que el deudor haya actuado con mayor o menor buena fe a juzgar por los actos que haya realizado». El precepto autoriza al juez a valorar esta diversidad de comportamientos y, en función de ellos — «según los casos»—, fijar el quantum indemnizable conforme $\mathrm{al}$ art. $1107.1^{\circ} \mathrm{CC}$, pero, debe decirse, lo hace sin fijar elementos de juicio que pauten el ejercicio de esta facultad y faciliten su control.

\section{EL CARÁCTER DISCRECIONAL DE LA FACULTAD DE MODERACIÓN Y LA EXCLUSIÓN GENERAL DE LA REVISIÓN CASACIONAL}

La exclusión general del control en casación de las decisiones que hacen uso de la facultad del art. 1103 CC se ha sustentado sobre dos argumentos relacionados: una consolidada interpretación jurisprudencial del significado de la discrecionalidad judicial ${ }^{22}$, y la invocación de la función propia del recurso de casación, que sería esencialmente contrario a dicha admisión ${ }^{23}$.

\section{EL CARÁCTER DISCRECIONAL DE LA FACULTAD DE MODERACIÓN DEL ART. 1103 CC}

La decisión de cuándo y con qué alcance debe hacerse uso de la facultad de moderación del art. 1103 CC es tarea encomendada al juez,

21 SAP Madrid, 12a , de 27 de noviembre de 2014 y SAP Madrid, 11, de 29 de marzo de 2019.

22 Para Kelsen (1934) la indeterminación constitutiva del derecho supone el reconocimiento a la autoridad judicial de un margen de discrecionalidad a la hora de resolver, ya sea concedido intencionalmente, ya sea la consecuencia involuntaria de la propia imprecisión o ambigüedad de la norma.

23 Ya en la STS de 29 de mayo de 1897 se afirma el carácter discrecional de la facultad moderadora que el art. 1103 CC atribuye a los tribunales. 
y se hace precisa para poder medir, conforme al art. 1104 CC, las consecuencias del incumplimiento culposo, obligando a apreciar, si no lo ha hecho la propia obligación, qué conducta se hubiera ajustado según las circunstancias a una diligencia media o normal para fijar equitativamente sus consecuencias.

El carácter de decisión basada en la equidad ha constituido para la jurisprudencia justificación suficiente para defender la discrecionalidad del juzgador de instancia en el ejercicio de la facultad moderadora que establece el precepto y su principal consecuencia: la facultad moderadora no esta sujeta a reglas, sino al prudente arbitrio del juzgador de instancia, por lo que, con indicación a su aplicación o inaplicación, no es susceptible de recurso de casación ${ }^{24}$, lo que, se afirma, resulta coherente con la misma función del recurso.

En consecuencia, la facultad moderadora recogida en el art. 1103 CC es, según la fórmula habitualmente empleada, «una facultad discrecional del Juzgador de instancia dependiente de las circunstancias del caso, no revisable en casación, y aplicable de oficio»" ${ }^{25}$. A la función «soberana ${ }^{26}$ del juzgador de instancia quedan reservadas cuestiones como la fijación de la cuantía de las indemnizaciones por resarcimiento de daños, la apreciación de la gravedad de las culpas compensables en los casos en que se aprecia concurrencia de culpas o la valoración de la prueba ${ }^{27}$.

La remisión a la apreciación discrecional por el juzgador de las circunstancias concurrentes se corresponde con un esquema de decisión que produce soluciones ajustadas al caso dentro del espacio reservado a la soberanía judicial $^{28}$, pero resulta insuficiente para resolver las cuestiones que plantea

24 Entre las más recientes, SS de 19 de mayo de 2010, 17 de junio de 2010 y 13 de diciembre de 2017.

25 STS 615/2012, 23 de octubre.

26 Fernández Rodríguez (2005: 32-33) atribuye a un déficit de tratamiento teórico del arbitrio judicial que este «siga considerándose en general insusceptible de control alguno como expresión de lo que, de forma tan frecuente como irritante, se califica a menudo por el Tribunal Supremo como una facultad soberana de aquellos».

27 Para Fernández Rodríguez (2005: 91-100), en materia de valoración de la prueba la ley no concede al juez libertad de elección alguna, aunque de facto se ejerza la discrecionalidad y se impida el control de la misma.

28 Lifante Vidal (2012: 144) aborda una reconstrucción del concepto de poder discrecional que lo caracteriza, no como ausencia de regulación, sino como «un tipo de regulación específica consistente en la presencia de normas que han de ser interpretadas como «mandatos de optimización» y que lo que hacen es marcar el fin objetivo [...] que debe perseguir la conducta, optimizando para ello los recursos disponibles 
el uso de la facultad moderadora del 1103 CC que requieren una precisa delimitación del concepto de discrecionalidad y de sus límites, sobre todo por la importancia de la consecuencia inmediata que se le asocia: el rechazo como regla general, a la revisabilidad de las decisiones mediante el control en casación de la aplicación —o falta de aplicación — de la facultad de moderación de la indemnización realizada por el tribunal de instancia.

Esta concepción resulta, sin embargo, difícil de justificar, en relación con la prohibición general de la arbitrariedad de los poderes públicos del art. 9.3 $\mathrm{CE}$, que exige que toda discrecionalidad se encuentre jurídicamente vinculada y que su correcto ejercicio sea sometido como regla general al control, precisamente, del tribunal de casación.

\section{LA FUNCIÓN PROPIA DEL RECURSO DE CASACIÓN}

La función propia del recurso de casación ha servido al Tribunal Supremo, tanto como fundamento para determinar si en un caso concreto se ha hecho uso de la facultad de moderación con infracción del art. 1103 CC como, en general, para rechazar la posibilidad misma de la revisión casacional ${ }^{29}$.

El modelo del recurso de casación que acoge nuestro ordenamiento jurídico persigue, como ha reiterado la jurisprudencia ${ }^{30}$, el control de la aplicación correcta del ordenamiento jurídico ${ }^{31}$ a los hechos que integran el supuesto litigioso, conforme se hayan declarado probados por el tribunal de instancia por el resultado de su valoración de los medios de prueba, a fin de que, como resultado de dicha verificación, el órgano competente corrija la

para conseguirlo». El órgano destinatario de la norma, afirma, pasa a ser el responsable de la determinación de los medios óptimos mediante juicios evaluativos que pueden y deben estar sometidos a control.

29 Armenta Deu (2018: 1-49). El debate sobre el significado y función propias del recurso de casación es prácticamente inagotable. En los modelos de configuración de la casación intervienen no solamente enfoques procedentes de distintas ramas del derecho, tradiciones y sistemas jurídicos, sino también otros elementos que vinculan su eficacia a su conexión con la realidad social y un sustento ideológico presente desde su origen conceptual, en la Revolución francesa.

30 SS de 25 de junio de 2010, 14 de abril de 2011, 5 de mayo de 2011, 4 de abril de 2012, 22 de julio de 2014.

31 Y no, o no principalmente, una hermenéutica de la norma que, más allá de la justicia del caso concreto, busque proyectarse hacia el futuro, orientando a los tribunales inferiores y procurando la seguridad jurídica y la predictibilidad de las decisiones (ibid.: 10). 
decisión alcanzada o, en su caso, unifique o defina la doctrina jurisprudencial sobre una materia, asegurando así el sometimiento del juez a la ley ${ }^{32}$.

En la doctrina, Cuenca Gómez (2008: 143) ha atribuido también a la casación la función de evitar la quiebra de la seguridad jurídica y preservar la certeza y la predecibilidad de las decisiones judiciales, como formas de garantizar para los individuos la calculabilidad de sus decisiones y la libre elección de planes y proyectos de vida.

La concepción asentada por el Tribunal Supremo de la casación, no como una tercera instancia, sino como un recurso extraordinario que persigue la pureza del ordenamiento jurídico mediante el control de la correcta aplicación de la norma jurídica a los hechos declarados probados ${ }^{33}$ tiene consecuencias, como advierten Montero y Flors (2018: 525, 526), en cuanto a la formación de los motivos del recurso e impide reconstruir en la casación los hechos según la propia elaboración de los mismos por el recurrente, exigiendo, en cambio, plantear las cuestiones jurídicas respetando los hechos probados y su valoración y sin alterarlos.

La técnica casacional exige centrarse en razonar sobre la infracción legal, prescindiendo de los hechos y de la valoración probatoria, que se considera función exclusiva de la instancia, y no es susceptible de revisión, salvo que, por ser manifiestamente arbitraria o ilógica, no supere el test de racionalidad constitucionalmente exigible para entender respetado el derecho a la tutela judicial efectiva (art. 24 CE).

Pero, además, la casación exige el respeto a los pronunciamientos discrecionales, facultativos o de equidad, que constituyen materia reservada «a la soberanía» del tribunal de instancia ${ }^{34}$, a salvo los supuestos en que el uso de la facultad de moderación resulte arbitrario, ilógico o contrario a derecho, lo que ha permitido fundar el rechazo del recurso de casación ex art. 1103 CC en el propio carácter de dicha facultad. Su uso por la instancia se basa en el ámbito que el propio precepto reconoce a la discrecionalidad judicial y encuentra, como se ha expuesto, límites para su control casacional, pues la función de control en la interpretación y la aplicación de la norma y la creación de doctrina jurisprudencial propias del recurso no pueden cumplirse sin aquel respeto.

32 STC 230/1993, de 12 de julio. La unificación de la jurisprudencia para conseguir una interpretación uniforme del ordenamiento constituye, según la Circular 1/2020 de la Fiscalía General del Estado, el objeto del recurso.

33 STS de 7 de mayo de 2012.

34 SSTS 663/2017 de 13 de diciembre de 2017 y 123/2015, de 4 de marzo de 2015. 
Sin embargo, la regla no puede afirmarse de forma absoluta, pues también el poder discrecional de la instancia conoce límites, como el propio Tribunal Supremo y, sobre todo, el Tribunal Constitucional reconocen, y está, en todo caso, sujeto a justificación.

La exclusión de la casación del uso de la facultad de moderación judicial del art. 1103 CC, justificada en la propia función del recurso y excepcionada solo cuando concurre evidente y notorio error de hecho o cuando la instancia ha resuelto de forma caprichosa, desorbitada o injusta, contribuye, precisamente, a dificultar el control de su ejercicio, especialmente ante un uso tan amplio. Señala Fernández Rodríguez (2005: 104-105) en esta dirección que «la afirmación de la irrevisabilidad en casación tanto del ejercicio de la facultad moderadora como de la apreciación de la cuantía en que debe moderarse (sentencia de 10 de marzo de 1995) se refuerzan siempre en un ejercicio tautológico que ahorre cualquier otra explicación, con cita de la larga lista de decisiones que dicen exactamente lo mismo».

\section{SUPUESTOS DE ADMISIÓN DEL CONTROL CASACIONAL}

Aunque la jurisprudencia admite desde antiguo excepciones a la regla de la exclusión del control casacional del uso de la facultad moderadora del art. 1103 CC, una amplia casuística hace difícil aflorar con claridad —más allá de las cuestiones puramente procesales - los criterios empleados por el Tribunal Supremo para abrir paso al recurso contra estas decisiones.

Lo que puede constatarse del examen de la jurisprudencia es que desde los inicialmente admitidos se han ido incorporando otros supuestos en los que, por distintos motivos, se ha estimado preciso abrir esta vía. Algunas de estas excepciones son resultado de la aplicación de las reglas propias del recurso, en tanto que otras se refieren específicamente al uso, o la falta de uso, de la facultad reconocida por el art. 1103 CC y al modo en que, a juicio del Tribunal Supremo, debe aplicarse y motivarse.

No obstante la ampliación de los supuestos de admisión, el control casacional se reserva aún en la jurisprudencia, invariablemente, a supuestos excepcionales, en los que «a simple vista se adivina que su determinación es ilógica o irracional ${ }^{35}$ y queda excluido, por lo tanto, cuando la aplicación de esta facultad no da lugar a esos resultados.

A la progresiva admisión de estos supuestos de excepción se añade una mayor atención a la necesidad de preservar el carácter discrecional de

35 STS 1104/2006, de 20 de diciembre. 
las decisiones evitando, al mismo tiempo, la arbitrariedad. Esta solución se obtiene reclamando la exteriorización de los parámetros de aplicación o inaplicación de la facultad de moderación como parte de la exigencia de motivación de la decisión judicial.

La consecuencia es que, aunque la jurisprudencia prevé solo excepcionalmente la posibilidad de revisión casacional del uso de la facultad del art. 1103 CC, esta se admite en más supuestos de los que la formulación general da a entender, pues para que quede vedado el acceso a la casación el tribunal de instancia debe haber observado en su aplicación reglas que restringen el uso de la discrecionalidad que el precepto reconoce, asegurando un resultado legal y justo.

El Tribunal Supremo, no obstante, no ha elaborado una doctrina en relación con estos supuestos excepcionales, sino que, en función de las circunstancias del caso, ha encontrado justificado, por razones procesales o sustantivas, revisar el uso o aplicación de la facultad moderadora realizado por la instancia.

De hecho, con frecuencia, en los casos en que se casa la sentencia de la instancia lo que hace el Tribunal Supremo es hacer uso él mismo de la facultad moderadora del art. 1103 CC cuando entiende que la Audiencia lo hizo incorrectamente o que dejo de hacerlo sin motivo, y lo hace sustituyendo su valoración y corrigiendo un resultado que, en el caso concreto, considera inequitativo atendido el resultado, es decir, por conducir a un resultado irracional, ilógico, desproporcionado o arbitrario.

Conviene por lo tanto examinar los supuestos en los que, por excepción, se viene admitiendo el control en casación del uso de la facultad moderadora y de la fijación del quantum indemnizatorio, con el fin de extraer elementos que permitan entender mejor las condiciones y limitaciones de su ejercicio.

\section{A. Cuando en la aplicación de la facultad de moderación ha existido una desproporción notoria o una aplicación con criterio contrario al ponderado, racional y lógico}

La excepción más frecuentemente admitida a la regla general se refiere a los supuestos en que se ha producido una «desproporción notoria» o una aplicación del art. 1103 CC con criterio contrario al «ponderado, racional y lógico».

La STS de 19 de mayo de 1996 se cita a menudo en la jurisprudencia posterior como la resolución que abrió «en cierto modo y limitadamente» la posibilidad del recurso de casación al afirmar que, si bien el uso de la posibilidad de moderación que ofrece el art. 1103 CC es facultad propia de los juzgadores de la instancia, no susceptible de casación, esto se refiere al supuesto 
en que los mismos hagan uso de tal facultad «con criterio ponderado, racional y lógico, pero no cuando extravasen irracional o desmesuradamente dichos parámetros $[\ldots]$ ».

La excepción se introduce a la regla general, reiterada en la práctica totalidad de las decisiones ${ }^{36}$, de que la del art. 1103 CC constituye una facultad discrecional y exclusiva de la instancia, de modo que la casación solo procede cuando las bases fácticas en las que se asienta la moderación aplicada «no son correctas, suficientes y resultan equivocadas»" ${ }^{37}$. Para la jurisprudencia, se trata de casos excepcionales de manifiesta falta de lógica o de resultados absurdos, como cuando se aplica la moderación en casos en que el resultado dañoso constituyó una actuación dolosa, y no meramente indiligente ${ }^{38}$.

La STS 724/2008, de 17 de julio de 2008, confirma en este sentido la regla general de que la Sala de apelación no está sujeta a baremo tasado a la hora de fijar el quantum indemnizatorio y excluye la aplicación del art. 1103 CC del ámbito de la casación, a menos que se haya hecho uso de tal facultad "de modo irracional y desmesurado" ${ }^{39}$. En un sentido positivo, pues, lo que se advierte es que la casación está vedada cuando los tribunales de instancia hagan uso de tal facultad "con criterio ponderado, racional y lógico» ${ }^{40}$.

La tarea de explicitar estos parámetros ha venido dificultada por la propia redacción del precepto, en el que no se contienen, pero también por la función que el propio Tribunal Supremo asigna al recurso de casación, al que esta anudada la exigencia de respeto a los pronunciamientos discrecionales, facultativos o de equidad, que solo pueden discutirse cuando se ha incurrido en error notorio o arbitrariedad o, en lo que se refiere a la cuantía, cuando se infringe el ordenamiento en la determinación de las bases tomadas para su fijación ${ }^{41}$.

36 SSTS de 17 de noviembre de 1995, 20 de mayo y 4 de noviembre de 2004, 19 de julio de 2007 y 10 de octubre de 2007, entre otras muchas.

37 SSTS de 15 de febrero de 1994, 18 de mayo de 1994, 23 de noviembre de 1999 y 5 de diciembre de 2000.

38 STS de 10 de julio de 2007.

39 SSTS de 19 de julio y 31 de diciembre de 1996, 5 de diciembre de 2000 y 6 de noviembre de 2002, 4 de noviembre de 2004, 20 de julio de 2006, 22 de enero, 30 de noviembre, 25 de enero y 17 de diciembre de 2007, 317/2010, de 19 de mayo, 17 de junio de 2010, las SSTS 606/2011, de 20 de julio, STS 538/2012, de 26 de septiembre.

40 SSTS de 19 de mayo y 17 de junio de 2010, 20 de julio de 2011, 26 de septiembre de 2012, 28 de mayo de 2015, 13 de diciembre de 2017.

41 SSTS de 15 de febrero y 18 de mayo de 1994, 21 de diciembre de 2006, 30 de julio de 2008, 31 de mayo de 2011 y 19 de febrero de 2014. 
Aunque no sea lo frecuente, algunas decisiones abordan la cuestión de cuándo el uso de la facultad de moderación indemnizatoria puede entenderse realizado al margen de ese criterio ponderado, racional y lógico. La STS 663/2017, de 13 de diciembre, por ejemplo, opone al uso que desborda dichos parámetros aquel en el que la moderación constituye la conclusión lógica de una detallada valoración de la prueba y de una acertada apreciación del nexo causal que conduce como resultado a una moderación legal y justa.

Las «circunstancias del caso» modulan, por indicación del propio precepto, el uso de la facultad de moderación, pero conviene notar que, al mismo tiempo, actúan como límite: ¡es susceptible de revisión en casación la facultad ejercida cuando no se ajusta a lo que resultaría exigible según las circunstancias del caso, o la expresión sirve solo para aclarar que se trata de una facultad discrecional, dependiente solo de la apreciación de las circunstancias concurrentes y que solo corresponde al juez?

Así pues, para que la casación sea viable es necesario que la prueba practicada evidencie la desproporción de responsabilidades, pues esta solo puede apreciarse atendiendo al factum establecido como probado, que ha de ponerla de manifiesto ${ }^{42}$. Y dado que el supuesto básico es una desproporción entre la conducta del agente y el daño que provoca un desequilibrio de prestaciones que ha de ser corregido, la existencia de dicho desequilibrio debe también ser puesta de relieve a nuestro juicio, pues de lo contrario fallaría la base que autoriza la aplicación de la solución de equidad y, en última instancia, la discrecionalidad del juzgador en el caso concreto.

\section{B. Cuando ni siquiera se plantee la posibilidad de hacer uso de dicha facultad si la misma viene forzosa y lógicamente impuesta por las especiales circunstancias concurrentes}

La segunda excepción, a menudo unida a la anterior, se refiere al caso en que el tribunal ni siquiera se haya planteado la posibilidad de hacer uso de dicha facultad, si la misma viene "forzosa y lógicamente impuesta» por las especiales circunstancias concurrentes en el supuesto concreto que se enjuicia.

La mencionada STS de 19 de mayo de 1996 admitió este supuesto de excepción, y el mismo criterio se expresa en una abundante jurisprudencia posterior $^{43}$. Así, en la STS 317/2010, de 19 de mayo de 2010, el Tribunal

42 SSTS de 5 de julio de 1993, 6 de febrero y 17 de julio de 2008 y 19 de mayo de 2010.

43 Siguiendo el criterio de las SSTS de 19 de julio de 1996, 19 y 20 de octubre de 1997 , 2 de noviembre de 1999 y especialmente 30 de noviembre y 10 de octubre de 2007, 19 de mayo y 17 de junio de 2010, 28 de mayo de 2015. 
Supremo recordó que la doctrina de la Sala no excluye absolutamente la revisión de la moderación regida por el art. 1103, «entre otras ocasiones, cuando $[\ldots]$ ni siquiera se plantee en la decisión judicial la posibilidad de hacer uso de dicha facultad, si la misma viene forzosa y lógicamente impuesta por las especiales circunstancias concurrentes en el supuesto concreto que se enjuicia —SSTS de 19 de julio de 1996, 20 de octubre de 1997 y 2 de noviembre de 1999».

En esta misma dirección, la STS 612/1996, de 19 de julio, abrió paso a la revisión casacional por no haberse hecho uso de la facultad moderadora cuando resultaba procedente su aplicación por entender que la negligencia imputable podía ser calificada de levísima, ni haber explicitado la sentencia recurrida razón alguna por la que no consideró procedente aplicarla.

Si la facultad de moderación ha de ejercitarse según las circunstancias del caso, entonces resulta lógico admitir que, cuando las que concurren lo exigen, no hacer uso de dicha facultad resulta inequitativo y falla la base misma o el fundamento de su concesión, por lo que se justifica la revisión casacional.

Ahora bien, la apreciación de que las circunstancias concurrentes exigían «forzosa y lógicamente» el uso de la facultad moderadora es una apreciación que se realiza a posteriori por el propio Tribunal Supremo, que actúa supliendo la actividad de la instancia, y para la que no bastará en nuestra opinión la simple inaplicación, sino que requerirá, de un lado, de una amplia base de evidencia derivada del factum probado que convierta, atendidas las circunstancias, la falta de uso de dicha facultad en un acto erróneo y, de otro, de la falta de motivación o de motivación suficiente en la sentencia de la decisión de no aplicar la facultad moderadora.

La doctrina jurisprudencial según la cual la aplicación de la facultad moderadora puede resultar forzosa constituye un límite a la discrecionalidad de la instancia, pues las circunstancias del caso no actúan solamente como soporte o base fáctica de la actividad discrecional del juzgador, sino que pueden también restringirla haciendo imperativo el uso de la facultad de moderación.

La falta de uso de la facultad de moderación del art. 1103 puede obedecer a una amplia casuística: por haber sido la conducta dolosa y no negligente, por no tratarse del ejercicio de una acción de resarcimiento de daños, sino de una pretensión de cumplimiento del contrato, o, en los casos en que se aduce concurrencia de culpas, por entender que recae toda ella sobre uno de los causantes ${ }^{44}$. Dado el fundamento del precepto, puede deberse también a que no se aprecie la desproporción necesaria entre la conducta y el daño causado, o a no haberse producido un desequilibro de prestaciones que exija

44 SAP Vizcaya de 10 de mayo de 2019. 
ser corregido por la equidad, a que su aplicación comportaría un enriquecimiento injusto, e incluso puede simplemente estar basada en la experiencia de los tribunales, cuyas valoraciones pueden alcanzar la categoría de máximas de la experiencia ${ }^{45}$.

\section{En los casos de concurrencia de culpas, cuando el debate no trata tanto de la fijación cuantitativa de la indemnización como de discernir el grado y naturaleza del respectivo aporte de culpabilidad}

La aplicación del art. 1103 CC en los casos de concurrencia de culpas se traduce en una moderación de la cuantía de la indemnización cuando se aprecia, junto con la culpa del propio obligado, la conducta concurrente de otros sujetos. Requiere, pues, una valoración de la gravedad de las culpas compensables que, según la jurisprudencia, corresponde al tribunal $a q u o^{46}$, quien tiene la facultad de moderar la responsabilidad del agente reduciendo la cuantía de la indemnización, repartiendo el daño con el perjudicado, sin que su decisión sea, como regla general, recurrible en casación ${ }^{47}$.

También en este caso existe una línea jurisprudencial constante que, como excepción al criterio anterior, admite entrar en el examen de la procedencia y la proporción en que se aprecia la concurrencia de las conductas cuando está en cuestión la apreciación del necesario nexo causal y de la efectiva participación culposa o negligente de las partes, o se aprecia una notoria desproporción en la distribución de las responsabilidades concurrentes que desconoce la gravedad de la que resulta más decisiva ${ }^{48}$, cabiendo entonces discutir en casación dichos extremos, a condición de que se hayan sentado en la instancia las bases necesarias para valorarlos.

En los supuestos en que se aprecia concurrencia de culpas, la revisión casacional es también posible por causa de la falta de aplicación de la facultad moderadora a la que nos hemos referido ${ }^{49}$.

45 SAP Cáceres, $1^{\text {a }}$, de 26 de febrero de 2019.

46 SSTS de 13 de febrero de 1971, 7 de octubre de 1988, 3 de diciembre de 1990, 7 de junio de 1991, 5 de julio de 1993, 23 de febrero de 1996 y 18 de julio de 2006

47 SSTS de 9 de febrero de 1990, 3 de marzo de 1998 y 17 de septiembre de 1998, 15 de diciembre de 1999, 29 de septiembre de 2005, 28 de junio de 2006 y 20 de julio de 2011, entre otras.

48 Entre otras, SSTS de 30 de diciembre de 1991, 25 de febrero de 1992, 28 de mayo de 1993, 12 de julio de 1995 y 10 de mayo de 2006 y 10 de octubre de 2007.

49 STS de 30 de noviembre de 2020, en un caso en el que, producido un siniestro aéreo, no se había moderado la responsabilidad de Mapfre, aseguradora de responsabilidad civil de Air Comet, cuando, a juicio del tribunal, dicha responsabilidad debía 


\section{Por apreciación arbitraria o contraria a la lógica o al buen sentido del nexo causal}

Entre las cuestiones excluidas de la posibilidad de revisión en casación se encuentra la de la existencia misma de nexo causal entre el daño y la actuación negligente del agente por la posible concurrencia de la propia culpa del perjudicado, como presupuesto de toda responsabilidad y con independencia del título de atribución. Dicho nexo ha de ser probado con certeza y no a través de meras conjeturas, deducciones o probabilidades — aunque en ocasiones resulte suficiente un juicio de probabilidad cualificada- y su apreciación corresponde al tribunal de instancia, por lo que ha afirmado la jurisprudencia que «la causalidad física, material o fenomenológica, antes que jurídica o imputación objetiva, es una cuestión de hecho que, como tal, es función propia de la instancia, y resulta ajena, por tanto, al control casacional $»^{50}$.

Sin embargo, una jurisprudencia constante ${ }^{51}$ admite que también la apreciación del nexo causal puede ser atacada en casación si es arbitraria o contraria a la lógica o al buen sentido.

\section{E. Por aplicación indebida del art. 1103 CC para moderar la indemnización en supuestos en que se ha previsto una cláusula penal que no cabe moderar al amparo del art. $1154 \mathrm{CC}$}

El Tribunal Supremo ha declarado la procedencia del recurso de casación en relación con el art. 1103 CC cuando lo que se cuestiona no es el ejercicio de la facultad discrecional de moderación, sino que en el supuesto concreto, en el que no puede moderarse conforme al art. 1154 CC, cupiera ejercitarla (STS 615/2012, de 23 de octubre), declarando que la facultad discrecional prevista en el art. 1103 CC no puede operar frente a lo convenido por las partes.

Como la dispuesta en el art. 1103 CC, la facultad judicial de moderación ex art. 1154 CC se considera una facultad soberana del tribunal de instancia ${ }^{52}$,

distribuirse entre Air Comet y Aena al $50 \%$, al no poderse concretar el grado de participación de cada una en la producción del daño.

50 STS 88/2014, de 19 de febrero.

51 SSTS 30 de noviembre de 2001, 7 de junio y 23 de diciembre de 2002, 29 de septiembre y 21 de diciembre de 2005, 19 de junio, 12 de septiembre, 19 y 24 de octubre de 2007, 13 de julio de 2010, entre otras.

52 STS 417/2015, 29 de junio de 2015, SSTS de 9 de octubre de 2000, 28 de febrero de 2001, 7 de febrero de 2002, 20 de diciembre de 2006, STS, Sala de lo Civil, 691/2018, de 11 de diciembre, entre otras. 
basada en la equidad e irrevisable en casación ${ }^{53}$, si bien su ámbito de aplicación está restringido por el propio precepto: la norma está prevista para el caso de que, regulada la pena para el supuesto de incumplimiento total de la obligación, el cumplimiento sea parcial o irregular. Ello implica que el juez no podrá entrar a moderar la cláusula penal cuando la obligación se haya incumplido totalmente ${ }^{54}$, pero tampoco cuando la cláusula está prevista precisamente para el incumplimiento que se ha producido ${ }^{55}$, o cuando se está ante un simple retraso en el supuesto de cláusula penal moratoria ${ }^{56}$.

La voluntad de las partes al establecer la cláusula penal constituye el elemento central para decidir, pues cuando está establecida para un determinado incumplimiento, aunque fuera parcial o irregular, no puede aplicarse la facultad moderadora del art. 1154 CC si se produce exactamente la infracción prevista, lo que afecta a la finalidad misma de la norma que «[...] no reside en rebajar equitativamente la pena por resultar excesivamente elevada, sino en interpretar que las partes, al pactar la pena, pensaron en un incumplimiento distinto del producido» (STS, Pleno, 530/2016, de 13 de septiembre de 2016).

La cuestión que nos resulta de mayor interés es la de si, prevista una cláusula penal inmoderable al amparo del art. 1154 CC, la indemnización puede ser objeto de moderación ex art. 1103 CC, así como si en tales casos la inaplicación o la indebida aplicación de la norma puede abrir paso al control casacional, posibilidad esta negada por la misma STS de 16 de septiembre de 2016, «mientras el legislador no tenga por conveniente modificar el vigente artículo $1154 \mathrm{CC}^{57}$.

La RDGRN de 28 de julio de 2016, en relación con una cláusula penal incumplida totalmente, señaló, recogiendo jurisprudencia anterior ${ }^{58}$, que en estos casos no procede la moderación de la pena ex art. 1154 CC, pero

53 SSTS de 30 de enero de 1932, 11 de marzo de 1957, 24 de noviembre de 1970, 4 de julio de 1981, 30 de junio de 1981 y 11 de mayo de 1982. Sin embargo, señala González Pacanowska (2021: 1191) que «sí cabe plantear como cuestión jurídica la correcta o incorrecta aplicación del artículo 1154, es decir la concurrencia de uno de sus presupuestos». Véase STS 317/2020, de 17 de junio, allí citada.

54 STS de 21 de febrero de 2014.

55 STS 1151/2018, de 12 de julio.

56 STS 1293/2007, de 5 de diciembre.

57 Anteriormente, STS 196/2015, de 17 de abril.

58 SSTS de 30 de abril de 2013 (con cita de la de 4 de enero de 2007), 585/2006, de 14 de junio, 962/2008, de 15 de octubre, 211/2009, de 26 de marzo, 170/2010, de 31 de marzo, 470/2010, de 2 de julio, 384/2009, de 1 de junio, 170/2010, de 31 de marzo y 615/2012, de 23 de octubre, entre otras. 
tampoco cabe hacer uso de la facultad prevista en el art. 1103 CC, aunque se hubiera debido a una conducta negligente; pero no porque esta no proceda en caso de incumplimiento total de la obligación, sino "porque rige la fuerza vinculante del pacto, que constituye una forma de tutela reforzada del crédito, frente a la que la facultad prevista en el art. 1103 CC no puede operar».

Se ha planteado si esta doctrina debe mantenerse también en los casos en que la pena es excesiva, es decir, sin proporción entre la prevista y los daños y perjuicios causados por el incumplimiento, pues tales cláusulas podrían estimarse abusivas para el deudor, e incluso determinar un enriquecimiento injusto para el acreedor ${ }^{59}$.

Una jurisprudencia ha admitido en casos de incumplimiento no esencial del acreedor que hace uso de la cláusula penal a su favor que se proceda a una "compensación» fundada en el artículo $1103 \mathrm{CC}$, que queda confiada al prudente arbitrio del tribunal sentenciador. Así, la STS 136/2019, 1a a de 6 de marzo $^{60}$ la concedió en relación con un contrato de arrendamiento de local de futura construcción que la arrendataria se negó a recibir por haberse retrasado la arrendadora en la entrega y en la que, resuelto el contrato, se reclamaba por aquella el pago de las rentas. La decisión atendió al incumplimiento previo de la arrendadora y a otras circunstancias, como la posibilidad de arrendar nuevamente el local en un breve plazo, para moderar la cláusula penal.

No se trata en este último caso de una verdadera moderación, sino de una "compensación» que remite a un juicio de equidad, dejado al arbitrio del juez según las circunstancias y cuyo anclaje en el art. 1103 CC se justifica solo en la imposibilidad de aplicar la regla moderadora del art. $1154 \mathrm{CC}^{61}$. La distinción es pertinente, pues la moderación viene ligada al menor grado de culpa del agente y no, simplemente, a la valoración como excesiva de la cantidad solicitada para la reparación del daño causado.

Más allá de los supuestos resueltos, puede concluirse que cabe la revisión de la facultad moderadora del art. $1103 \mathrm{CC}$ en aquellos casos en los que se debate sobre la concurrencia de los presupuestos para su ejercicio - por ejemplo, si existe una desproporción entre el daño causado y la conducta del agente que requiera ser corregido por medio de un pronunciamiento de equidad—, y no solo si se ha hecho uso correcto de dicha facultad.

59 STS 175/2017, de 25 de enero, SAP Barcelona, 11 de abril de 2019.

60 Con cita de las SSTS 629/2010, de 28 octubre, y 29 de marzo de 2004.

61 STS 284/2019, de 21 de junio. Por respeto al principio de autonomía de la voluntad y a la fuerza vinculante de los contratos, rechaza el TS el uso de la potestad judicial moderadora. 
Aunque insistiremos en esta idea, conviene señalar que la admisión de estos supuestos viene a reconocer la imposibilidad de que el ejercicio de la facultad de moderación del art. 1103 CC, como el de otros supuestos, escape al control del correcto ejercicio del poder discrecional que la norma otorga cuando no establece o no puede establecer de forma directa la consecuencia jurídica.

Lo que hace el Tribunal Supremo a través de los supuestos enumerados es fijar los límites de la extensión de su propio control a falta de elementos de juicio que puedan extraerse del art. 1103 CC y, generalmente, sustituir la valoración de la instancia por la suya propia, con el fin de obtener una solución que considera más equitativa.

\section{LÍMITES A LA DISCRECIONALIDAD JUDICIAL: «DISCRECIONALIDAD PERMITIDA» VS. «DISCRECIONALIDAD ARBITRARIA»}

La discrecionalidad de los pronunciamientos judiciales está sujeta a los límites impuestos por la necesidad de evitar la arbitrariedad de las decisiones y de preservar la tutela judicial efectiva, y por su medio, la igualdad y la seguridad jurídica y el derecho de defensa ${ }^{62}$, entendido este último como un poder jurídico del litigante en un proceso ${ }^{63}$, «de provocar la actividad procesal necesaria para lograr la convicción del órgano judicial sobre la existencia o inexistencia de los hechos relevantes para la decisión del conflicto objeto del proceso" ${ }^{64}$.

El estudio de los límites de la facultad de moderación del art. 1103 CC y de la posibilidad de su revisión requiere una mejor comprensión de los límites

62 Para Fernández Rodríguez (2005: 60-61) dicho poder está siempre condicionado implícitamente por el fin de la norma habilitante y, además, por los criterios o pautas que ésta pueda eventualmente imponer expresamente y por la densidad de regulación que establezca, que es distinta en cada caso.

63 SSTC 37/2000, de 14 de febrero, 19/2001, de 29 de enero y 133/2003, de 30 de junio, acogida por el Tribunal Supremo (STS 217/2019 de 21 de febrero).

64 Ahora bien, no es ese proceso psicológico de convicción del juzgador el que satisface el derecho de las partes amparado en el art. $120 \mathrm{CE}$, sino una justificación suficiente específicamente dirigida a motivar la decisión de usar o no de la facultad del art. 1103 CC. Iguartúa Salaverría (2001: 465 y ss.) ha sugerido la conveniencia de sustituir el "convencimiento del Juez» por los «hechos probados», pues ambos actúan en dos planos distintos — psicológico y racional- que no siempre marchan paralelos. 
a la discrecionalidad ${ }^{65}$ que puede abordarse a partir de la confrontación, planteada por la jurisprudencia, entre una "discrecionalidad permitida" por el art. 1103 CC y una "discrecionalidad arbitraria» que desbordaría los límites reconocidos por el precepto a la actuación judicial y abriría paso al control casacional de las decisiones ${ }^{66}$.

La facultad que recoge el art. 1103 CC se ejerce discrecionalmente, esto es, reconoce al juez un margen de libertad que consiste en la facultad de elegir entre dos alternativas jurídicas, pero no autoriza un uso ilimitado de esta potestad, sino un uso necesariamente condicionado o limitado, desde luego por el fin mismo perseguido por la norma que la concede y por la obligación de tener en cuenta todas las circunstancias del caso $^{67}$, pero también por la elaboración jurisprudencial acerca de cuándo y cómo debe utilizarse y por la prohibición general de la arbitrariedad que impone en todos los casos rendir cuentas de su uso.

En el primer aspecto, la SAP Barcelona, 11, 134/2019, de 6 de marzo de 2019, por ejemplo, limita la facultad de moderación autorizada por el art. 1103 CC a tres supuestos que se han ido configurando por la jurisprudencia: «cuando se produce una conducta concurrente en la producción del resultado lesivo por parte de la víctima [...] cuando el afectado tiene el deber legal o convencional de mitigar el daño, o para evitar una situación de enriquecimiento injusto para el perjudicado» ${ }^{68}$.

En el segundo aspecto, la precisión de un concepto de la arbitrariedad en el que el uso o no de la facultad moderadora implique una decisión que no quedaría amparada por los márgenes reconocidos a la discrecionalidad judicial en esta materia, conviene acudir a la elaboración del concepto por el Tribunal Constitucional, que permite el encaje del supuesto previsto en el art. 1103 $\mathrm{CC}$ con mayor facilidad que otras concepciones.

La apreciación de una discrecionalidad arbitraria exige dos presupuestos o requisitos vinculados, sin los que la revisión en casación no es posible: de un lado, que la cuestión se haya suscitado en la instancia y, de otro, que en

65 Sobre la necesidad de fiscalización de la discrecionalidad en las decisiones judiciales y el empleo de los principios jurídicos en el ámbito constitucional, véase Ruiz Ruiz (2010: 119 y ss.).

66 Tener potestad discrecional y ejercerla son dos cosas distintas, como afirma Waluchow (1983: 321-339).

67 Señala Castán (1953: 107 y ss.) que el poder discrecional propio de la equidad delegada puede ser más o menos extenso, pero nunca un poder arbitrario, sino limitado por las normas de delegación.

68 En el mismo sentido las SSAP Barcelona, 11 y 19 de diciembre de 2019 y 6 de marzo de 2019. 
ella se hayan fijado las bases fácticas y jurídicas que permitan al tribunal de casación decidir si la resolución recurrida puede considerarse enmarcada en la discrecionalidad que autoriza el art. 1103 CC.

En efecto, para poder verificar en la casación si el uso de dicha facultad muestra una desproporción notoria o una aplicación con criterio contrario al ponderado, racional y lógico, o una falta no justificable de aplicación, la sentencia recurrida debe haber fijado las bases fácticas en las que se asienta la moderación practicada. Es esta fijación la que permite establecer la corrección del quantum indemnizatorio fijado ${ }^{69}$.

$\mathrm{Si}$, conforme al art. 477.1 ${ }^{\circ}$ LEC, el motivo o los motivos del recurso han de respetar el ámbito de discusión jurídica habida en la instancia, el planteamiento en el recurso de cuestiones nuevas alteraría el objeto de la controversia privando a la parte contraria de oportunidades de alegación y prueba, afectando a su derecho de defensa ${ }^{70}$. Confirma el criterio la Circular 1/2020, de 3 de enero, de la Fiscalía General del Estado, que afirma que la casación «se da contra la sentencia dictada en apelación y no contra la de primera instancia, sin que puedan reproducirse en el mismo cuestiones que no se plantearon en la alzada y que, en consecuencia, integran cuestiones nuevas (STS 691/2018, de 11 de diciembre, con cita de múltiples precedentes)».

La consecuencia práctica es que la discusión, jurídica o fáctica, sobre el uso de la facultad prevista en el art. 1103 CC no puede introducirse por primera vez en la casación, porque es contrario a su naturaleza que en este recurso se planteen cuestiones nuevas, sobre las que los tribunales de instancia no hayan podido pronunciarse.

La STS de 18 de octubre de 2019 expresa este criterio, al declarar que la revisabilidad de las decisiones basadas en el ejercicio de esta facultad requiere que pueda considerarse que el tribunal de instancia incurrió en arbitrariedad y presupone «[...] que la cuestión se haya suscitado en la instancia y que los tribunales de instancia hayan fijado las bases fácticas y jurídicas que permitan al tribunal de casación decidir si la decisión del tribunal de apelación ha de considerarse enmarcada en la discrecionalidad que le permite el art. 1103 del Código Civil [...]».

Para cumplir esta exigencia no basta con que la cuestión esté presente en la instancia, sino que es imprescindible que lo esté en la sentencia de apelación, pues «si lo que se cuestiona en casación es el uso de la facultad moderadora en supuestos de incumplimiento doloso, en cuanto tal contravención no arranca

69 SSTS 15 de febrero de 1994, 18 de mayo de 1994, 23 de noviembre de 1999 y 5 de diciembre de 2000.

70 ATS de 16 de marzo de 2016 y las SSTS allí citadas. 
ni tiene su origen en la Sentencia de apelación sino que ya estaba presente en la de primera instancia, para que el examen casacional fuera posible debería haberse suscitado tal cuestión en segunda instancia [...]» (STS 346/2009 de 20 de mayo).

La cuestión es común al recurso de apelación en el que, conforme al principio pendente apellatione, nibil innovetur, no cabe plantear cuestiones nuevas, ni fácticas ni jurídicas, ni tampoco formular pretensiones distintas de las ejercitadas en la primera instancia ${ }^{71}$, incluidas no solo las que resulten totalmente independientes de las deducidas, sino también las que las alteren o complementen.

\section{LA REVISIÓN CASACIONAL POR INCUMPLIMIENTO DEL DEBER DE MOTIVACIÓN EN USO DE LA FACULTAD DEL ART. 1103 CC}

\section{LA EXIGENCIA DE MOTIVACIÓN DE LAS DECISIONES Y EL CONTROL DE LA POTESTAD DISCRECIONAL DEL ART. 1103 CC}

La doctrina, con distintos matices, ha puesto de relieve la necesidad de motivación de las decisiones que hacen uso de la facultad moderadora del art. 1103 CC para hacer posible su control casacional, planteando una excepción general de especial interés a la irrevisabilidad de las decisiones discrecionales o de equidad vinculada al derecho a la tutela judicial efectiva del art. $24 \mathrm{CE}$.

Díaz Alabart (1988: 1205) señaló la necesidad de motivación de las razones que llevaron al juzgador de instancia a la decisión en aplicación del art. 1103 CC, si bien, en su opinión, la mayoría de las decisiones de instancia mencionan dichas razones y normalmente, aunque no se especifiquen, la causa de justificación se desprende de los hechos ${ }^{72}$.

Asúa González (2013: 8086) ha establecido a efectos de la impugnabilidad una distinción entre las cuestiones fácticas y las de otro orden, de modo que:

[...] debería justificarse con que se trata, cuando se trate, de cuestiones fácticas

—entonces efectivamente solo procedería la revisión en caso de criterio irracional

$71 \quad$ STS de 29 de septiembre de 2016.

72 Cita la STS de 30 de junio de 1981, en la que se planteó la cuestión de la necesidad de motivación del uso de la facultad discrecional del art. 1103 CC, y, aunque se casó la sentencia de la Audiencia porque no había ofrecido las razones para moderar, entiende Díaz Alabart que la decisión se debió realmente a que no se apreciaron razones para hacer uso de la moderación, más que al hecho de que no se explicitaran. 
o desmesurado-, pero no en el carácter discrecional de la facultad. En algunos casos se tratará efectivamente de cuestiones fácticas, pero en otras no. Podrá ser una cuestión fáctica la determinación de la concreta contribución causal de dos comportamientos, pero no, por ejemplo, si se imputa objetivamente un daño o si una conducta es negligente. En estos supuestos la cuestión está plenamente abierta a la casación.

La decisión judicial ha de ajustarse, obviamente, a un canon de racionabilidad y a la proscripción de cualquier decisión arbitraria o infundada. Ahora bien, la verificación de dicho ajuste solo puede hacerse sobre la exteriorización en la resolución de los criterios tenidos en cuenta en el ejercicio de la facultad de moderación de la indemnización o de los empleados para decidir que no procede emplearla ${ }^{73}$, de modo que se satisfaga el derecho de las partes en el proceso y se posibilite el control jurisdiccional de la decisión.

Si la razón de ser del art. 1103 CC radica en la valoración judicial de una situación en la que tiene lugar un desequilibrio de prestaciones que, por resultar injusto, ha de ser corregido, la sentencia debería, al menos, exteriorizar, o dejar deducir con evidencia estos elementos ${ }^{74}$.

La facultad de moderación se concede, precisamente, por la dificultad que entraña el establecimiento de la cuantía de la indemnización en los casos en que interviene negligencia y reclama, como contrapartida, la exteriorización de parámetros claros que justifiquen las razones jurídicas de la decisión y la forma de su ejercicio. En este sentido, la apelación a la discrecionalidad como «facultad soberana», cualquiera que sea el margen de libertad reconocido, no puede servir, como advierte Fernández Rodríguez (2005: 69), "para enervar la exigencia constitucional de justificación de las resoluciones judiciales y negar la propia posibilidad de revisión de las mismas».

En tanto que la discrecionalidad implica ejercicio de un poder delegado por la norma bajo determinadas circunstancias y con un fin, la motivación de la decisión judicial puede considerarse también una forma de rendir cuentas del modo en que se ha ejercitado. De hecho, como ha señalado Igartúa Salaverría (2001: 459), el art. 120.3 CE y su exigencia de que las sentencias sean siempre motivadas «está provisto de suficiente dosis normativa, de manera que se basta por sí solo para imponer la obligación de motivar las sentencias», pero, además, constituye un mandato «que se legitima por su aptitud insustituible

73 Para un difícil inventario de criterios que justificarían en uso de la facultad moderadora del art. 1103 CC, véase Díaz Alabart (1988: 1223-1224).

74 Sobre la reducción de la discrecionalidad en la aplicación de los principios jurídicos, sujetándola a un procedimiento racional optimizado por medio de un orden débil de principios, Alexy (1988: 140 y ss.). 
para asentar elementos centrales de la mampostería constitucional y para dar vida a capitales derechos fundamentales».

Cómo pueda verificarse si la resolución contiene una motivación suficiente que satisfaga el derecho de las partes y, en su caso, haga viable su control mediante la interposición de los recursos correspondientes, es cuestión que debe examinarse, en relación con el significado del derecho a la tutela judicial efectiva y la jurisprudencia que lo interpreta, tanto constitucional como civil, en ocasiones directamente referida a la cuestión de la moderabilidad judicial de la indemnización por negligencia.

\section{TUTELA JUDICIAL EFECTIVA Y FUNCIÓN DE CONTROL CASACIONAL DE LOS PRONUNCIAMIENTOS DISCRECIONALES, FACULTATIVOS O DE EQUIDAD. LA EXPRESIÓN DE LOS PARÁMETROS DE DECISIÓN}

El derecho a la tutela judicial efectiva sin indefensión es el derecho reconocido por igual a todas las personas con derecho e interés legítimo a acudir a un órgano judicial para, entre otras facultades, recibir una respuesta motivada y fundada en derecho a las alegaciones y pretensiones de las partes en el proceso siempre que hayan cumplido los requisitos previstos en las leyes procesales a la hora de presentarlas ${ }^{75}$. Como fundado en una exigencia de la convivencia, se trata de un derecho de prestación: la Constitución obliga al Estado a proporcionar a las personas que demandan justicia una respuesta efectiva sus pretensiones, y su garantía está encomendada a los órganos jurisdiccionales.

El Tribunal Constitucional ha consolidado en esta materia una doctrina de la que a menudo se ha hecho eco el Tribunal Supremo. La STC 6/1992, de 16 de enero, ya concretó el derecho que tienen todas las personas al acceso a los órganos jurisdiccionales y a obtener de ellos una respuesta motivada. Esta doctrina tiene un amplio desarrollo en la jurisprudencia constitucional posterior. Así, para la STC 25/2012, de 27 de febrero, la exigencia de que el órgano judicial ofrezca respuesta a las pretensiones formuladas por las partes a lo largo del proceso, responde a la necesidad de evitar un desajuste entre ellas y el fallo judicial, el cual tiene lugar, entre otros casos, cuando queda sin respuesta alguna, siempre que no quepa interpretar razonablemente el silencio

75 Carrasco Durán (2018: 369, 370, 372-375) señala que el Tribunal Constitucional desglosa esta vertiente del derecho en el derecho a una resolución motivada y el derecho a que esa motivación no sea arbitraria, irrazonable o adolezca de error patente, si bien en ocasiones el derecho a la tutela judicial se utiliza sin diferenciar los términos. 
como desestimación tácita, cuya motivación pueda inferirse del conjunto de los razonamientos contenidos en la resolución.

La tutela judicial efectiva comporta el derecho de conocer los criterios jurídicos que fundamentan la decisión para evitar la irracionalidad y la discrecionalidad y posibilitar su control. Es preciso acudir de nuevo a la doctrina constitucional para recordar que dicha motivación —en la práctica, una auténtica justificación - consiste en la exteriorización del iter decisorio o conjunto de consideraciones racionales que justifican el fallo, por lo que se presenta como una exigencia constitucional (art. 120.3 CE) y como un deber inherente al ejercicio de la función jurisdiccional ${ }^{76}$, no como una mera formalidad.

La respuesta judicial a las pretensiones planteadas mediante un razonamiento congruente fundado en derecho no garantiza, señala la doctrina del Tribunal Constitucional, el acierto judicial, pero evidencia que el fallo no es un simple y arbitrario acto de voluntad del juzgador ${ }^{77}$.

La finalidad que cumple la exigencia de motivación se ha cifrado, de una parte, en su función de garantía: que puedan conocerse tanto por las partes interesadas como por los integrantes del llamado sistema jurídico interno y por la sociedad, las razones que han llevado al órgano jurisdiccional a dictar su resolución; y, de otra, en la posibilidad para los legitimados de hacer uso de los medios de impugnación establecidos, es decir, garantizar la posibilidad de control de la resolución ${ }^{78}$.

El doble carácter, de obligación y de derecho, de esta exigencia ha sido puesto de manifiesto, entre otras, por la STS 217/2019, de 21 de febrero, que recuerda que la motivación de las sentencias que impone el art. 218 de la LEC se dirige tanto a las partes como a los órganos revisores, de modo que «no es sólo una obligación impuesta a los órganos judiciales por el art. 120.3 CE, sino también, y principalmente, un derecho de los intervinientes en el proceso [...], que únicamente se satisface si la resolución judicial, de modo explícito o implícito, contiene los elementos de juicio suficientes para que el destinatario y, eventualmente, los órganos encargados de revisar sus decisiones puedan conocer cuáles han sido los criterios jurídicos que fundamentan la decisión».

Podemos entonces entender que una resolución contiene una motivación suficiente cuando satisface las dos finalidades indicadas. Para ello no es exigible una respuesta judicial pormenorizada a cada una de las alegaciones de las

76 STS 557/2015, de 20 de octubre, con cita de la STC 144/2003 de julio y la STS de 5 de diciembre de 2009.

77 STC 24/1990, de 15 de febrero.

78 La STS 790/2013 de 27 de diciembre se refirió a esta doble finalidad. 
partes ni a cada una de las pruebas aportadas. Basta para cumplir la exigencia constitucional de motivación que la resolución contenga un razonamiento lógico y coherente, aunque sea sucinto, que permita invocar ${ }^{79}$ los criterios jurídicos esenciales fundamentadores de la decisión, la ratio decidendi, y que se anude con los extremos sometidos por las partes a debate (STC 101/92, de 25 de junio), incluso si tiene lugar por remisión o motivación aliunde ${ }^{80}$ (SSTS 4/2021, de 4 de enero y 27 de febrero de $2020^{81}$ ).

Lo relevante es, pues, que la motivación, aunque escueta, sea bastante para comprender los elementos que el juzgador ha tenido en cuenta para llegar al resultado o exprese las razones de hecho y de derecho que los funda$\operatorname{mentan}^{82}$.

Por otra parte, la vulneración del derecho a la tutela judicial efectiva puede también traer causa de una valoración ilógica, irracional o arbitraria de la prueba,planteándose en estos casos el recurso al amparo del art. 469.1.4 ${ }^{\circ}$ $\mathrm{LEC}^{83}$, pues aunque la valoración de la prueba se considere una función exclusiva de los tribunales de la instancia no revisable, supone en estos casos un incumplimiento del "test de racionabilidad constitucionalmente exigible» para respetar el derecho a la tutela judicial efectiva ${ }^{84}$.

Ahora bien, aunque la formulación jurisprudencial parece clara, no acierta a hacerse cargo de la complejidad de la cuestión del control casacional de las decisiones, sobre todo cuando la falta de motivación se plantea, como sucede en el caso del art. 1103 CC, en relación con pronunciamientos discrecionales, facultativos o de equidad, considerados materia reservada al tribunal de instancia. Como hemos señalado, el Tribunal Supremo ha venido entendiendo que el uso de la facultad del art. 1103 CC se encontraba suficientemente amparado por la discrecionalidad reconocida al juez en el caso concreto, de modo que bastaba con una expresión, aunque fuese sucinta, de la razón que determinaba dicho uso, o con que esta pudiera deducirse de

79 SSTS 294/2012, de 18 de mayo, 95/2014, de 11 de marzo, 759/2015, de 30 de diciembre, 459/2019, de 22 de julio, 491/2019, de 24 de septiembre y 570/2019, de 4 de noviembre, 2 de marzo de 2020, 264/2020, de 8 de junio, 4/2021, de 14 de enero, entre otras.

80 SSTC 108/2001, de 23 de abril, y 171/2002, de 30 de septiembre.

81 Reiterada en las de 2 y 12 de marzo de 2020.

82 SSTS de 15 de febrero de 1989, 30 de abril de 1991 y 7 de marzo de 1992.

83 En cambio, la revisión de las valoraciones jurídicas extraídas de los hechos probados solo puede ser objeto del recurso de casación (STS 322/2015, de 23 de septiembre, FJ 15).

84 Según la STS de 18 de febrero de 2015, el 218.2 LEC responde a una lógica de la argumentación en orden a justificar la decisión, sin extenderse a su acierto o desacierto. 
los hechos, sin necesidad de ulterior motivación de la decisión y que, en tanto que pronunciamiento discrecional, no cabía su revisión en casación por falta de motivación.

La cuestión fue objeto del voto particular formulado por el magistrado Ignacio Sancho Gargallo en la STS 669/2012, $1^{\circ}$, de 14 de diciembre de 2012, disintiendo del criterio mayoritario de la Sala ${ }^{85}$, la cual, sobre la base de la amplia discrecionalidad que la norma atribuye al Juez, aplicó la doctrina que deja fuera del recurso los pronunciamientos discrecionales, facultativos o de equidad.

Señaló el voto particular que la consecuencia de esa asentada doctrina es la falta de seguridad jurídica, pues la discrecionalidad deja de serlo cuando no existen parámetros claros que justifiquen su ejercicio, y que el ordenamiento jurídico civil conoce otros supuestos en que se deja a la apreciación discrecional del juez el alcance de una determinada responsabilidad (como ocurre con el art. 1154 CC o el 1726 CC), pero siempre es en función de un parámetro claro y de una justificación lógica.

La conclusión es que la remisión a la discrecionalidad judicial discurre bajo determinados parámetros a emplear para su ejercicio, fijados por la propia norma o por la jurisprudencia. La ausencia de dichos parámetros impide la mínima previsibilidad del enjuiciamiento sobre la concreta responsabilidad que exige la seguridad jurídica, y, por ende, el mínimo control de su justificación.

\section{LA JUSTIFICACIÓN DE LA FORMA EN QUE SE ALCANZA EL QUANTUM INDEMNIZATORIO}

La necesidad de motivación de las decisiones en que se hace uso de la facultad del art. 1103 CC se extiende para el Tribunal Supremo a la fundamentación de la forma en la que se alcanza la cuantía indemnizatoria, rechazándose la fijación de una cantidad a tanto alzado, si bien, como veremos, dicha fijación no pertenece propiamente al ámbito de discrecionalidad judicial, sino que se encuentra más bien en dependencia de la prueba.

En el caso de la STS 790/2013 de 27 de diciembre, la Audiencia no consideró cumplidas las exigencias del derecho a la tutela judicial efectiva por razones que incluyen la falta de fundamentación de la moderación del quantum indemnizatorio, pues la sentencia «no llega a concretar las circunstancias que han de llevar a la fijación de la cantidad para la reparación ni

85 Siguiendo a la STS 501/2012, de 16 de julio. 
proporciona las bases que llevan a esta suma, limitándose el juzgador a invocar la facultad de moderación del artículo 1103 CC».

La misma exigencia referida a la expresión del modo en que se alcanzan en la sentencia unas cuantías y no otras se encuentra en la STS 441/2017 de 13 de julio de 2017, que conoció un caso en que se reclamaba indemnización por daños y perjuicios por negligencia profesional a un letrado que no había presentado una demanda dentro del plazo legalmente previsto. Argumentó el Alto Tribunal que no cabía equiparar a los efectos de quantum indemnizatorio la cantidad pretendida por el mismo en el proceso con la cantidad en que se cifra como indemnización por la negligencia profesional del letrado demandado ${ }^{86}$.

El Tribunal Supremo achacó a la sentencia recurrida incongruencia y falta de motivación, ya que la contenida:

[...] no expresa ni razona de forma clara cuáles son las circunstancias por las que fija a tanto alzado una determinada cantidad, y no otra, ni en qué concepto se le indemniza, con una motivación indudablemente ambigua en la que se mezcla el daño moral, el patrimonial y la pérdida de oportunidad para confirmar la sentencia del juzgado, [...] sin precisar qué oportunidades se perdieron para cuantificar de esa forma y no de otra el daño resultante de la negligencia profesional [...].

En la jurisprudencia menor esta motivación está presente en decisiones recientes como la SAP Coruña, 5a, de 8 de julio de 2020, que motiva el uso de la facultad moderadora del art. 1103 CC, expresando la manera en la que se ha llegado a la fijación de la cuantía indemnizable en función de un número de mensualidades de renta que determinaban el alcance del lucro cesante, o la SAP Lugo, 2a , 48/2021, de 29 de marzo, en un caso en que se había dañado el arbolado de una finca ajena mediante su tala, constatándose que, con posterioridad, el propietario de la finca había aprovechado parte de la madera talada.

\section{CONCLUSIONES}

De la jurisprudencia examinada resulta que la motivación y el señalamiento de las bases fácticas y jurídicas, de los criterios esenciales fundamentadores sobre los que se asentó la aplicación de la facultad de moderación judicial del art. 1103 CC, es la única forma de controlar en casación si dicho uso fue desmesurado o ilógico, y, por lo tanto, la única forma de que el

86 Para el Tribunal Supremo no hay en estos casos concreto daño patrimonial, sino daño moral. 
recurso pueda, precisamente, cumplir su función de descartar la arbitrariedad y preservar la tutela judicial efectiva y la seguridad jurídica que representa la predictibilidad de las decisiones.

Ello no significa, evidentemente, que el del art. 1103 CC no sea un pronunciamiento discrecional, sino solo que, como ha señalado la jurisprudencia constitucional ${ }^{87}$, la mera apelación a la discrecionalidad judicial no puede fundamentar que ni siquiera se pueda discutir en casación si la apreciación de responsabilidad concuerda con una correcta interpretación del precepto, pues toda discrecionalidad procede de la delegación de la norma y esta vinculada jurídicamente, aunque sea implícitamente. Tampoco excluye la necesidad de precisar el alcance del control que el Tribunal Supremo puede realizar en casación sobre la corrección o la incorrección del uso de la discrecionalidad realizado por la instancia en aplicación del art. 1103 del Código Civil, a fin de evitar que se desvirtúe la facultad que dicho precepto reconoce o que la casación se convierta en una tercera instancia.

Ahora bien, si el quantum de discrecionalidad librado al juez para hallar la solución más ajustada está en dependencia de la delegación de la norma y de los criterios o elementos de juicio a través lo que ésta lo circunscribe, la dificultad, o una de ellas, radica en que la norma del art. 1103 CC no establece los medios ni contiene criterios o elementos de juicio que sirvan a estos fines, sino que se limita a restringir su aplicación a los supuestos en que interviene negligencia, como presupuesto, y a afirmar que se llevará a cabo — podrá llevarse a cabo- «según los casos». Teniendo en cuenta que la intervención moderadora es también facultativa, esta última expresión tanto quiere decir que, según los casos, el tribunal tiene libertad para decidir si modera o no (lo que en realidad vendrá determinado por lo que resulte probado en el proceso), como que, si decide moderar, no hay establecidos criterios o parámetros que sirvan de guía a su labor, de modo que podrá hacerlo atenido solamente a lo que las circunstancias del caso aconsejen, a su arbitrio en suma, y a elementales criterios de racionalidad y razonabilidad.

Por consiguiente, la posibilidad de control jurisdiccional de las decisiones que hacen uso de la facultad moderadora del art. 1103 CC como consecuencia de los límites del propio poder discrecional procede no solo cuando la decisión extravase los términos de un "criterio ponderado, racional y lógico», se omita su uso sin justificación o concurran los demás supuestos señalados

87 Las SSTC de 14 de diciembre de 1992 y 18 de octubre de 2004 explicitan que el margen de discrecionalidad no constituye por sí mismo justificación suficiente de la decisión finalmente adoptada, sino que esta ha de estar motivada para posibilitar su control posterior. 
en los que el Tribunal Supremo ha apreciado la necesidad de ampliar la vía casacional. Procederá también, como parte del contenido del derecho a la tutela judicial efectiva, en los casos en que no se motive de forma específica, o no se motive suficientemente el modo en el que se ha hecho uso de esa facultad, la razón por la que procede y cómo, partiendo de qué bases, se ha llegado al quantum fijado - la justificación alcanza a ambos aspectos-, en especial si puede considerarse que esta falta de motivación ha conducido a una decisión irracional, ilógica o arbitraria.

Este resultado - es el resultado lo que importa - en el caso del art. 1103 puede proceder, entre otras causas, de la ausencia de fijación de los parámetros de decisión sobre los que debe discurrir el ejercicio de la facultad de moderación, de la ausencia de expresión comprensible para las partes de las razones por las que sientan las conclusiones del litigio o su fallo, o de las circunstancias y de las bases que conducen a la fijación de una determinada cantidad, y no de otra.

La fijación jurisprudencial de una doctrina unitaria de los límites del control casacional sobre el uso de la facultad de moderación judicial del art. 1103 CC puede hallarse dificultada por la ausencia de elementos o parámetros en el propio precepto que pauten su correcto ejercicio y permitan verificar su corrección y también por su consideración como pronunciamiento equitativo, pero esta ausencia ni excusa una motivación suficiente de las decisiones, que ha de incluir además del control de los elementos de racionalidad y racionabilidad exigidos por el art. 9.3 CE, un esfuerzo argumental y de justificación de la decisión, ni justifica una cláusula general contraria a la revisabilidad de estas decisiones, ni se resuelve simplemente sustituyendo el Tribunal Supremo la decisión del tribunal de instancia.

Dicho control constituye la última línea en la evitación de la arbitrariedad. La restricción excesiva de los supuestos de admisión de la revisión en casación —el mantenimiento de su carácter excepcional - tiene como base una criticable $-\mathrm{y}$ en buena medida superada — comprensión de la discrecionalidad judicial como práctica jurisdiccional que se justifica a sí misma o que encuentra amparo en la equidad, que debería ser corregida, como sostiene una doctrina constitucional bien consolidada sobre la exigencia de los arts. 9.3 y 120.3 CE.

El carácter de pronunciamiento discrecional no puede constituirse en obstáculo a la admisión como regla general de un recurso que, como respecto de los pronunciamientos discrecionales en otros órdenes jurisdiccionales, es esencial a la función de control de su correcto ejercicio y de interdicción de la arbitrariedad que los organismos jurisdiccionales tienen encomendada en garantía del derecho a la tutela judicial efectiva. 


\section{Bibliografía}

AA. VV. (2018). Propuesta de Código Civil. Asociación de Profesores de Derecho Civil. Madrid: Tecnos.

Albaladejo García, M. (2005). Sobre si la moderación de la responsabilidad del artículo 1103 del CC es o no aplicable a culpa extracontractual. Actualidad Civil, $1,5-24$.

Alexy, R. (1988). Sistema jurídico, principios jurídicos y razón práctica. Doxa, 5, 139-151. Disponible en: https://doi.org/10.14198/DOXA1988.5.07.

Armenta Deu, T. (2018). Recurso de casación: entre eficacia y nuevas orientaciones de fines tradicionales. InDret, 1, 1-49.

Asúa González, C. I. (2013). Artículo 1103 del Código Civil. En R. Bercovitz Rodríguez-Cano (coord.). Comentarios al Código Civil. Tomo VI (pp. 8078-8087). Valencia: Tirant lo Blanch.

Badosa Coll, F. (1987). La diligencia y la culpa del deudor en la obligación civil. Bolonia: Real Colegio de España.

- (1993). Artículo 1103 del Código Civil. En R. B. Rodríguez-Cano y N. Á. Lata. Comentario del Código Civil. Tomo II (pp. 38-40). Madrid: Ministerio de Justicia.

Carrasco Durán, M. (2018). El derecho a la tutela judicial efectiva sin indefensión. Navarra: Aranzadi Thomson Reuters.

Castán Tobeñas, J. (1953). La formulación judicial del Derecho y el arbitrio de equidad. Madrid: Reus.

De Diego, F. C. (1930). Instituciones de Derecho Civil Español. Madrid: Imprenta de Juan Pueyo.

Díaz Alabart, S. (1988). La facultad de moderación del artículo 1103 del Código Civil. Anuario de Derecho Civil, 41 (4), 1133-1224.

- (1989). Artículo 1103 del Código Civil. En M. Albaladejo García y S. Díaz Alabart (dirs.). Comentarios al Código Civily las Compilaciones Forales. Tomo XV, $1^{\circ}$. Madrid: Edersa.

- (2016). Sobre la moderación de las cláusulas penales. Comentario de la Sentencia del Tribunal Supremo de 17 de enero de 2012 (500/2012). En M. Yzquierdo Tolsada (coord.). Comentarios a las sentencias de unificación de doctrina: civil y mercantil (pp. 55-68). Madrid: Boletín Oficial del Estado.

Fernández Rodríguez, T. R. (2005). Del arbitrio y de la arbitrariedad judicial. Madrid: Iustel.

García Goyena, F. (1852). Concordancias, motivos y comentarios del Código civil español. Madrid: Imprenta de la Sociedad Tipográfico-Editorial.

González Pacanowska, I. (2021). Daños punitivos contractuales. Invalidez, reducción conservadora y moderación equitativa de la cláusula penal. En J. Ataz López y J. A. Cobacho Gómez (dirs.). Cuestiones clásicas y actuales del derecho de daños. Tomo II (pp. 1187-1224). Navarra: Aranzadi. 
Guilarte Martín-Calero, C. (1999). La moderación de la culpa por los tribunales (estudio doctrinal y jurisprudencial). Valladolid: Lex Nova.

Igartúa Salaverría, J. (2001). Motivación de las sentencias, presunción de inocencia, «in dubio pro reo». Anuario de Derechos Humanos, 2, 459-480.

Kelsen, H. (2011 [1934]). Teoría Pura del Derecho. Madrid: Trotta.

Lifante Vidal, I. (2012). Poderes discrecionales. Eunomía. Revista en Cultura de la Legalidad, 2, 139-144.

Montero Aroca, J. y Flors Matíes, J. (2018). El recurso de casación civil. Casación e infracción procesal. Valencia: Tirant lo Blanch.

Ossorio Morales, J. (1988). Lecciones de Derecho Civil. Obligaciones y Contratos. (Parte General). Granada: Comares.

Pantaleón, F. (1991). El sistema de responsabilidad contractual. Anuario de Derecho Civil, 44 (3), 1019-1091.

Pérez Velázquez, J. P. (2016). La indemnización de daños y perjuicios por incumplimiento del contralo en los Principios del Derecho Contractual Europeo. Madrid: Boletín Oficial del Estado.

Plaza Penades, J. (2016). Artículo 1103 del Código Civil. En R. Valpuesta Fernández (coord.), A. Cañizares Laso, P. de Pablo Contreras y F. J. Orduña Moreno (dirs.). Código Civil Comentado. Tomo III (pp. 114-116). Madrid: Civitas.

Pothier, R. J. (1839). Tratado de las Obligaciones. Barcelona: Imprenta y Litografía de J. Roger.

Rodríguez-Rosado, B. (2016). Acción de cumplimiento contractual de arrendamiento y facultad de moderación judicial. Comentario de la STS de 18 de marzo de 2016 (183/2016). En M. Yzquierdo Tolsada (coord.). Comentarios a las sentencias de unificación de doctrina: civil y mercantil, Tomo VIII (pp. 47-58). Madrid: Boletín Oficial del Estado.

Ruiz Ruiz, R. (2010). Sobre la discrecionalidad judicial en un Estado constitucional. Cuadernos Electrónicos de Filosofía del Derecho, 20, 119-132.

Waluchow, W. (1983). Strong discretion. The Philosophical Quarterly, 33 (133), 321 339. Disponible en: https://doi.org/10.2307/2219160. 